\title{
The effects of chemical components and particle size on the mechanical properties of binderless boards made from oak (Quercus spp.) logs degraded by shiitake fungi (Lentinula edodes)
}

\author{
Florence Hiu Yan Lui ${ }^{1} \cdot$ Yoko Kurokochi ${ }^{1} \cdot$ Hiroe Narita ${ }^{1} \cdot$ Yukie Saito $^{1} \cdot$ Masatoshi Sato ${ }^{1}$
}

Received: 27 September 2017 / Accepted: 22 December 2017 / Published online: 15 February 2018

(c) The Japan Wood Research Society 2018

\begin{abstract}
Binderless boards are composite boards that rely on self-bonding mechanisms for inter-fibre bonding. Quercus acutissima and Quercus serrata logs degraded by Lentinula edodes (shiitake fungi) were used in this study to investigate whether physical and chemical changes induced by shiitake fungi can enhance board mechanical properties. Binderless boards were manufactured with $0.8 \mathrm{~g} / \mathrm{cm}^{3}$ target density, $220^{\circ} \mathrm{C}$ pressing temperature, $5 \mathrm{MPa}$ pressure, and pressing duration of $10 \mathrm{~min}$. Boards made from logs degraded for $\geq 26$ months were stronger than control boards and met modulus of rupture (MOR) and internal bonding (IB) requirements for fibreboards. Chemical composition and particle size distribution of the wood powder used to make the boards were determined to elucidate the drivers of board mechanical properties. The proportion of small particles $(<150 \mu \mathrm{m})$ showed a strong positive correlation with MOR for both species and hot water extractives showed a strong positive correlation with IB for $Q$. acutissima boards. Introduction of shiitake fungi pre-treatment to the production process may enhance the mechanical strength of binderless boards.
\end{abstract}

Keywords Binderless board $\cdot$ Internal bonding $\cdot$ Shiitake $\cdot$ Degradation

\section{Introduction}

Wood-based composites are produced by combining wood strands, particles, fibres, veneers, or thin boards with adhesives or by other fixation methods. Medium density fibreboards (MDFs) have replaced traditional lumber in segments of the furniture and interior industry due to their relatively low cost and use of by-products from the lumber production process [1]. However, urea formaldehyde, a synthetic binder used for the production of MDFs and particleboards, may be carcinogenic and accounts for a large portion of manufacturing costs [2]. Binderless boards, a type of MDF that does not use synthetic binders, could potentially be a commercially viable and environmentally-friendly product in the MDF sector.

Yukie Saito

aysaito@mail.ecc.u-tokyo.ac.jp

1 Graduate School of Agricultural and Life Sciences, The University of Tokyo, 1-1-1 Yayoi, Bunkyo-ku, Tokyo 113-8657, Japan
Research on binderless boards has coincided with the drive for agro-industrial waste recycling and the development of ecomaterials. As such, the feasibility of using various agro-industrial waste to manufacture binderless boards has been investigated. Lignocellulosic agro-industrial byproducts, such as inter alia, kenaf core [3], oil palm biomass [4], moso bamboo [5], and rice straw [6] have been used to manufacture binderless boards. Although the exact determinants of the self-bonding mechanism are yet to be elucidated, the thermosetting behavior of lignin at elevated temperatures [7], polymerization of hot water extractives [8], particle size [9], and lignin-furfural resin formation [10] have been cited as possible causes of self-bonding between composite fibres.

Quercus spp. (oak) logs degraded by Lentinula edodes (shiitake fungi) were selected as the materials for this study because wood degraded by shiitake fungi has the merits of being a waste material from the mushroom cultivation process and a product of natural lignocellulosic enzymatic systems. The effect of enzyme pre-treatment on wood fibres for the production of binderless boards has been investigated [11], but the focus was on laccase, an oxidase enzyme that is specific to phenolic molecules in wood substrates. In 
addition to ligninolytic enzymes, shiitake fungi also contain cellulose and hemicellulose degrading enzymes that reduce polysaccharides to low molecular weight monomer and oligomer sugars for uptake [12]. There are many shiitake fungi induced chemical and physical changes in spent logs, two of which may potentially be favorable for binderless boards: (1) increase in hot water extractives, which can promote polymerization [8] and cross linkage [10] between various chemical components during the hot press process and (2) structurally weakened cells that may breakdown into smaller particles during the milling process, which can lead to a better particle packing system [9] with less voids and enhance stress transfer [13]. Furthermore, there is a large volume of waste logs produced by the mushroom cultivation industry [14]. Despite sawdust having a greater share of wood purchased for shiitake mushroom cultivation, spent logs were chosen as the materials for this study for better clarity over species origin and consistency in growing conditions, an important consideration for chemical component and particle size analysis.

The key research goal is to determine the mechanical properties of binderless board that have been made from wood degraded by shiitake fungi for varying durations during the mushroom cultivation process and how shiitake fungi induced changes in wood affects mechanical properties and internal bonding mechanisms of binderless boards.

\section{Materials and methods}

\section{Materials}

The samples were provided by MUSH-Shimura Noen in Shizuoka. The farm uses Quercus acutissima and Quercus serrata branches that are less than 11 years and have a diameter of c. $150 \mathrm{~mm}$ as log substrates for shiitake mushroom cultivation. The logs are typically felled in February and inoculated with shiitake spawn in March. Fruiting is stimulated in September by soaking the logs in cold water, after which mushroom harvesting starts. The logs are kept in greenhouses throughout winter. Mushroom yield varies throughout the cultivation period, but generally increases up to 2 years and then decreases; mushroom yields of this farm generally increased by c. $1.5 \mathrm{~kg}$ per log around 2 years and then decreased. The yield recovers by the third year when the bark softens sufficiently for shiitake fungi degradation. The logs are discarded after the fourth year of cultivation due to significant decreases in yield.

Undegraded logs and logs degraded by shiitake fungi for $2,14,26,38$, and 50 months were used as materials for this study. They were sterilized in an autoclave at $121^{\circ} \mathrm{C}$ for $1 \mathrm{~h}$ and dried in an oven at $105{ }^{\circ} \mathrm{C}$ until the moisture content (MC) reached $0 \%$. The logs, including inoculation points and spawn, were debarked, converted to wood powder (WP) using a Wiley Mill (WT-150; Miki Seisakusho, Japan) with a $1 \mathrm{~mm}$ screen mesh, and stored as a mix of homogenized WP. The hardness and density of the logs varied with degradation duration, a proxy for the degree of degradation; consequently, the time required to powderize the wood differed. Approximately $500 \mathrm{~g}$ of each sample was powderized to produce WP; WP that did not pass through the $1 \mathrm{~mm}$ screen mesh (less than $5 \%$ by weight) was excluded as waste WP. WP for the manufacture of boards and chemical analyses were sampled from the same mixture.

\section{Chemical composition}

Alcohol benzene extractives, hot water extractives, holocellulose, $\alpha$ cellulose (cellulose), and hemicellulose content was determined in accordance with the Wood Science Experiment Manual [15]. Lignin [16] and ash content [6] was determined in accordance with previously reported methods.

Alcohol benzene extractives were extracted by the soxhlet extraction method for $6 \mathrm{~h}$. Hot water extractives were removed by heating the sample in a water bath at $100{ }^{\circ} \mathrm{C}$ for $3 \mathrm{~h}$. Holocellulose was isolated by bleaching WP without extractives (defatted wood) in a water bath at $75^{\circ} \mathrm{C}$ for $3 \mathrm{~h}$; sodium chlorite and acetic acid were used as the bleaching agent and catalyst. Cellulose was isolated by mixing $17.5 \%$ $\mathrm{NaOH}$ aqueous solution with the sample in a water bath. Lignin content was determined by adding acid insoluble lignin isolated by $72 \%$ sulphuric acid (Klason Lignin) and acid soluble lignin (ASL) content. Klason Lignin was isolated by adding $72 \%$ sulphuric acid to defatted wood. The sample was put in a water bath for $3 \mathrm{~h}$ and stirred frequently. The concentration of the sample was reduced to $3 \%$ and treated in an autoclave at $121{ }^{\circ} \mathrm{C}$ for $30 \mathrm{~min}$. ASL content was determined spectrophotometrically by observing its absorptivity at $205 \mathrm{~nm}$. Ash was isolated by heating (oxidation) the sample in an electric furnace at $700{ }^{\circ} \mathrm{C}$ for $3 \mathrm{~h}$.

\section{Particle size distribution}

WP was separated into different particle size classes using an orbital sieve shaker (Electromag Sifter Pot Mill, Itoh, Japan) with sieve apertures of 500, 355, 250, and $150 \mu \mathrm{m}$. Approximately $10 \mathrm{~g}$ of WP was processed through the machine for $30 \mathrm{~min}$. The particle size distribution of WP samples was determined by weight.

\section{Board manufacture}

Binderless boards were manufactured according to a previously reported method [3]. The amount of wood particles used to manufacture each board was determined according to the target dimensions of the board $(300 \times 300 \times 5 \mathrm{~mm})$, target 
density $\left(0.8 \mathrm{~g} / \mathrm{cm}^{3}\right)$, and MC of WP. The average MC of WP was $7 \%$ and the minimum and maximum MC of WP was 4 and $8 \%$, respectively; the MC of WP ranged from 6 to $8 \%$ when the sample with MC of $4 \%$ was excluded. The relationship between MC of WP and the mechanical properties of the boards was examined, but there was limited correlation.

Binderless boards were made by dispersing WP to form a homogenous single-layer mat within a $300 \times 300 \mathrm{~mm}$ forming box. The mat was pressed at $220{ }^{\circ} \mathrm{C}$ and $5 \mathrm{MPa}$ for $10 \mathrm{~min}$ in a hot press machine (Model 1569; Komatsu, Japan). The relationship between actual board density and the mechanical properties of the boards was examined, but there was limited correlation.

\section{Evaluation of board mechanical and physical properties}

The modulus of rupture (MOR) and internal bonding (IB) tests were conducted with an universal testing machine (Model 4204; Instron; Canton, Massachusetts, USA) and in accordance with the guidelines in JIS Fiberboard Standard 5905-2014 [17]. Five specimens were tested and used to compute the average sample MOR and IB values and sample standard deviation.

Linear models were used to conduct correlation analysis on the mechanical properties of the boards, chemical components, and proportion of WP in various size classes. Additional statistical analyses were conducted to examine the effects of degradation duration and tree species on board mechanical properties. Analysis of variance (ANOVA) and all-pairwise comparisons tests (Tukey HSD) were conducted to investigate the variance within and between groups and to determine statistically homogenous groups.

\section{Results and discussion}

\section{Mechanical properties of the boards}

Figure 1 shows the results of the MOR test. The MOR values of both $Q$. acutissima and $Q$. serrata control boards (Q. acutissima: $3.0 \mathrm{~N} / \mathrm{mm}^{2}$ and Q. serrata: $3.2 \mathrm{~N} / \mathrm{mm}^{2}$ ) were much lower than the MOR of boards made from logs degraded for $\geq 14$ months. A gradual increase in MOR with degradation duration was observed. The highest MOR values were obtained from 38-month samples (Q. acutissima: $8.5 \mathrm{~N} / \mathrm{mm}^{2}$ and $Q$. serrata: $8.4 \mathrm{~N} / \mathrm{mm}^{2}$ ). MOR of boards made from logs degraded for 50 months ( $Q$. acutissima: $6.0 \mathrm{~N} / \mathrm{mm}^{2}$ and $Q$. serrata: $6.4 \mathrm{~N} / \mathrm{mm}^{2}$ ) was lower than 26-month and 38-month samples. The ANOVA test indicated that degradation duration had the greatest influence on MOR $(p<0.0001)$, while tree species did not have a statistically significant effect on MOR $(p=0.8006)$. The Tukey

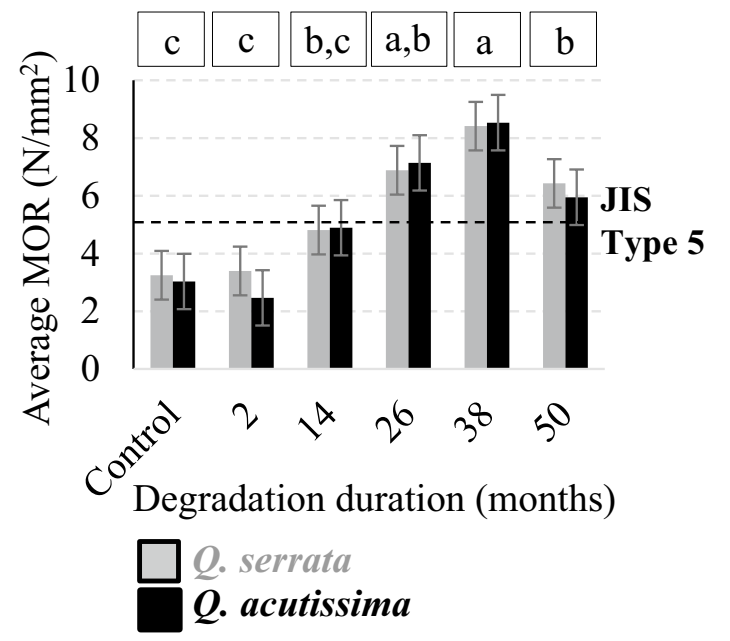

Fig. 1 Degradation duration of raw materials and MOR of boards made from $Q$. serrata and $Q$. acutissima WP. Bars indicate standard error and means marked with different letters (a, b, c) are significantly different at $p<0.05$ (Tukey HSD). Line marked as JIS Type 5 represents JIS standard threshold [17]

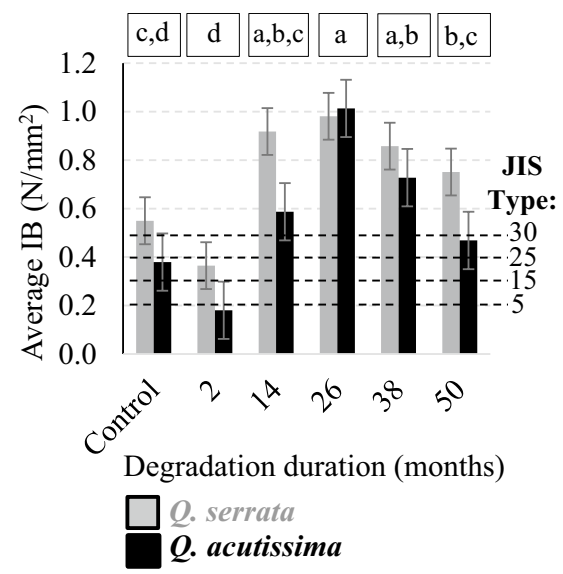

Fig. 2 Degradation duration of raw materials and IB of boards made from $Q$. serrata and $Q$. acutissima WP. Bars indicate standard error and means marked with different letters (a, b, c, d) are significantly different at $p<0.05$ (Tukey HSD). Lines marked as JIS Type 5-30 represent JIS standard thresholds [17]

HSD test indicated that boards made from logs degraded for $\geq 26$ months were statistically distinct from the control boards.

Figure 2 shows the results of the IB test. The lowest and highest values were obtained from boards made from logs degraded for 2 months (Q. acutissima: $0.18 \mathrm{~N} / \mathrm{mm}^{2}$ and Q. serrata: $0.36 \mathrm{~N} / \mathrm{mm}^{2}$ ) and 26 months (Q. acutissima: $1.01 \mathrm{~N} / \mathrm{mm}^{2}$ and $Q$. serrata: $0.98 \mathrm{~N} / \mathrm{mm}^{2}$ ), respectively. The ANOVA test indicated that degradation duration and tree species had a statistically significant effect on IB $(p$ for degradation duration and tree species were $<0.0001$ and 0.0031 , respectively). The Tukey HSD test indicated 
Fig. 3 Chemical content profiles of individual chemical components of $Q$. serrata and $Q$. acutissima WP (the $y$-axis (content) denotes proportion of each chemical component in WP); a alcohol benzene extractives; $\mathbf{b}$ hemicellulose; e holocellulose; and $\mathbf{f} \alpha$ cellulose hot water extractives; $\mathbf{c}$ lignin; d
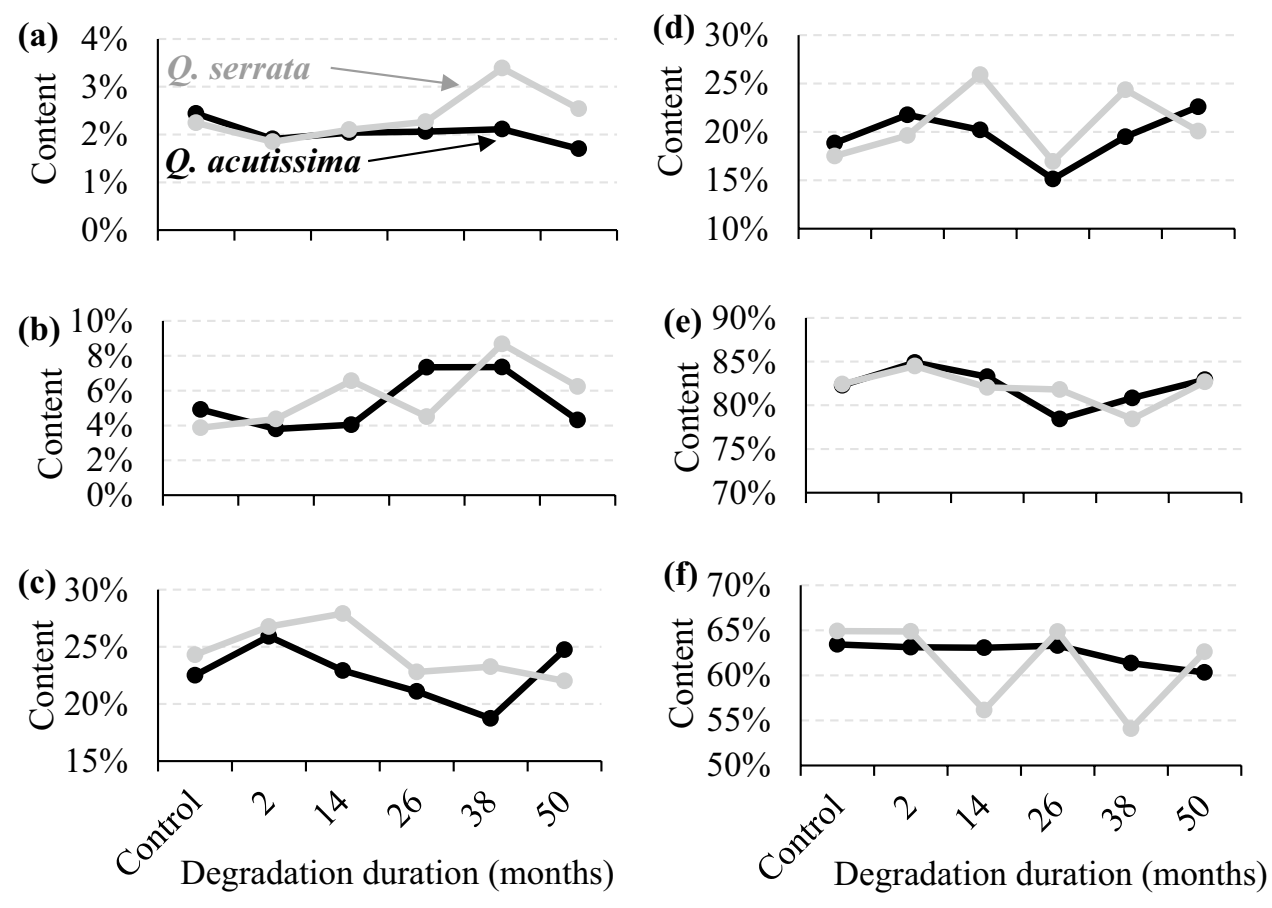

Fig. 4 Relationship between MOR of boards and individual chemical components of WP, on a species by species basis [the $x$-axis (content) denotes proportion of each chemical component in WP]; $\mathbf{a}, \mathbf{b}$ alcohol benzene extractives; $\mathbf{c}, \mathbf{d}$ hot water extractives; $\mathbf{e , f}$ hemicellulose; $\mathbf{g}, \mathbf{h} \alpha$ cellulose; and $\mathbf{i}$, j lignin

\section{Q. serrata}
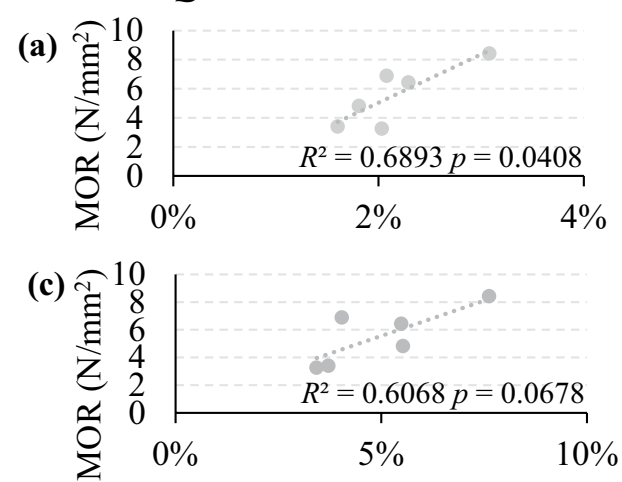

(e)

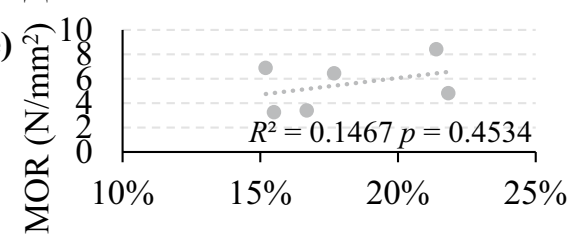

(g)

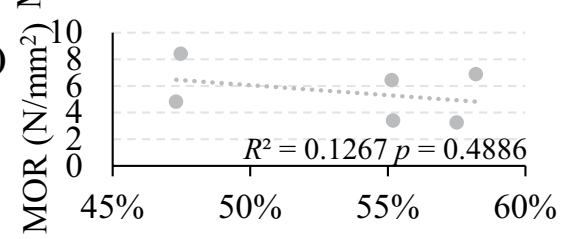

(i)

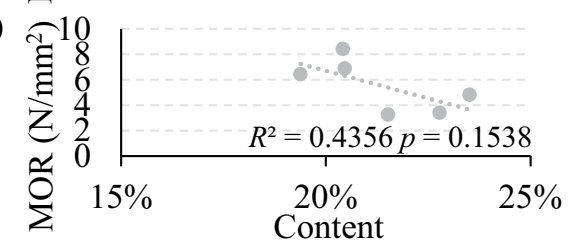

\section{Q. acutissima}

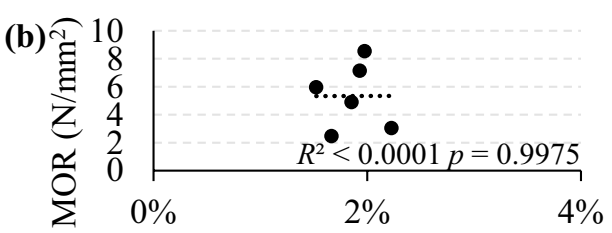

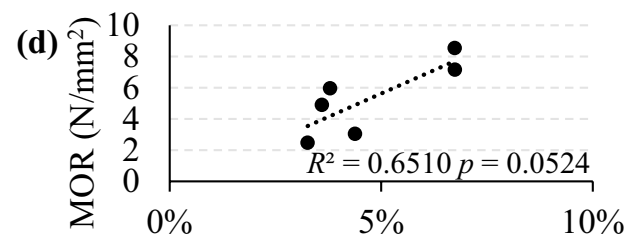

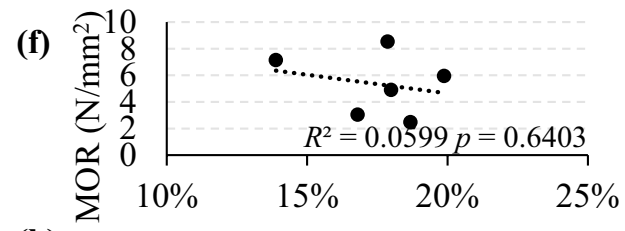

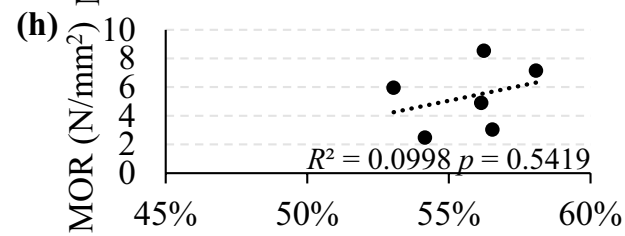

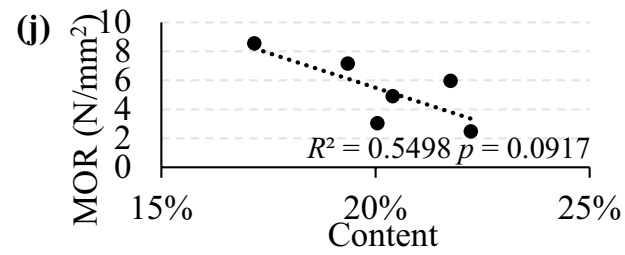


that boards made from logs degraded for 26-38 months were statistically distinct from the control boards.

Both species exhibited similar trends, where boards made from logs degraded for longer periods had higher MOR and IB values than the control. It is important to note that the logs do not represent a temporal study of changes to the same $\log$ s over 50 months, because they were inoculated in different years. The observed decrease in the 50-month samples may be due to a lower degree of degradation for that particular batch (due to unique climate, greenhouse, or handling conditions when they were inoculated, in 2012), rather than a reverse in degradation trends. The ANOVA test indicated that degradation duration had a statistically significant effect on MOR and IB. The Tukey HSD test indicated that boards made from logs degraded for longer durations ( $\geq 26$ months for MOR and 26-38 months for IB) were statistically distinct from control boards. These results suggest that the shiitake fungi degradation process induces changes in the oak logs that enhance binderless board mechanical properties.
In addition, JIS sets minimum MOR and IB requirements for fibreboards [17]. Boards made from logs degraded for $\geq 26$ months exceeded the JIS Type 5 MOR threshold of $5.0 \mathrm{~N} / \mathrm{mm}^{2}$, but the control boards and boards made from $\log$ degraded for $\leq 14$ months did not meet the requirements. All boards, with the exception of $Q$. acutissima boards made from 2-month WP, met the JIS Type 5 IB threshold of $0.2 \mathrm{~N} / \mathrm{mm}^{2}$. Boards made from logs degraded for 14-38 months even met the IB threshold for JIS Type 25 boards of $0.5 \mathrm{~N} / \mathrm{mm}^{2}$.

\section{Possible factors affecting board mechanical properties}

\section{Chemical components}

The chemical composition of $Q$. serrata and $Q$. acutissima WP was investigated (Fig. 3). The chemical composition of WP from logs degraded for differing durations did not show
Fig. 5 Relationship between IB of boards and individual chemical components of WP, on a species by species basis (the $x$-axis (content) denotes proportion of each chemical component in WP); $\mathbf{a}, \mathbf{b}$ alcohol benzene extractives; $\mathbf{c}, \mathbf{d}$ hot water extractives; $\mathbf{e}, \mathbf{f}$ hemicellulose; $\mathbf{g}, \mathbf{h} \alpha$ cellulose; and $\mathbf{i}$, j lignin
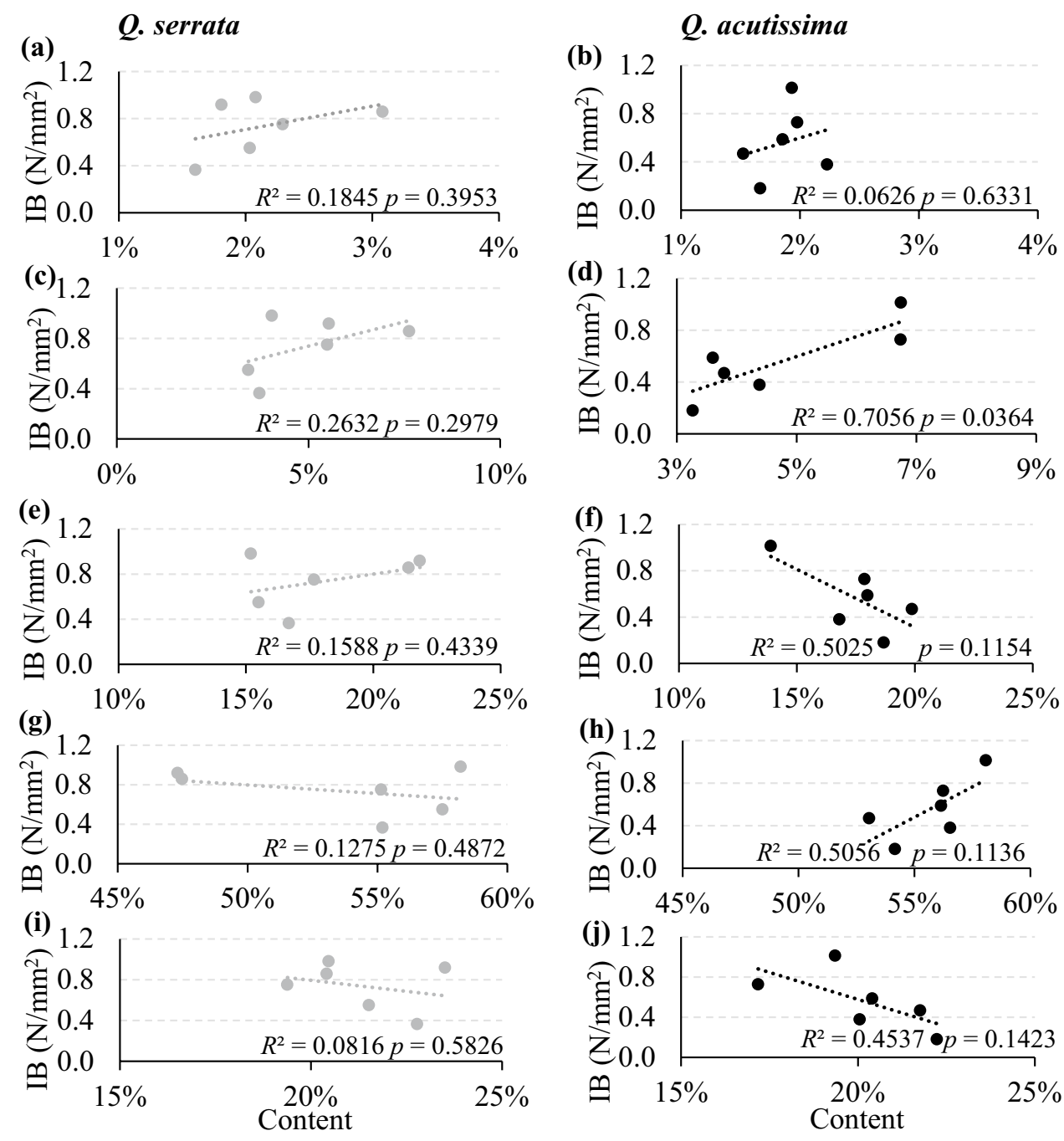
any consistent trends. Figure 3 suggests that the chemical components of shiitake degraded wood is not a time-dependent linear process. This is supported by previous studies, where different degradation rates and changes in the degradation rates were observed for each chemical component throughout the degradation process [12]. Consequently, the effect of time was excluded from the correlation analysis (Fig. 4).

The effect of chemical composition on MOR was investigated (Fig. 4). The correlation analysis indicated that hot water extractives content had a moderate positive correlation with MOR for both species $\left(Q\right.$. serrata: $R^{2}=0.6068$, $p=0.0678 ; Q$. acutissima: $\left.R^{2}=0.651, p=0.0524\right)$ and alcohol benzene extractives also had a moderate positive correlation with MOR, but for $Q$. serrata only $\left(R^{2}=0.6893\right.$, $p=0.0408$ ).

Natural variability in hot water extractives content, ranging from 3.3 to $8.0 \%$, has been reported for undegraded Japanese oak wood [18]. It has also been reported that shiitake degraded Quercus mongolica logs had higher hot water extractives content than undegraded logs [19]. The chemical composition of $Q$. acutissima and $Q$. serrata control samples in the present study are similar (Fig. 3), but differ greatly for degraded samples. Since shiitake fungi degrades wood polysaccharides into sugars for uptake [20], changes in hot water extractives content likely occur throughout the degradation process; it may either increase due to inefficient uptake of monomer and oligomer sugars from the breakdown of hemicellulose and cellulose, or decrease because the monomer and oligomer sugars are easily absorbed by the fungi. Nevertheless, the hot water extractive content of logs degraded for 2-50 months is likely at least partially driven by the shiitake degradation process. Furthermore, MOR is a measure of bending strength, which is positively impacted by the bonding of surface particles and negatively impacted by surface imperfections. Polymerization of monomer sugars, melting and filling in lumen voids, and crosslinking between the carbohydrates and lignin have been cited as possible ways hot water extractives promote internal bonding [8]. Previous studies that added glucose and sucrose to control samples found that the xylose/arabinose ratio decreased, indicating that the monomer sugars polymerized during the hot press process [8]. Mechanical interlocking and fusion of fibres were observed in the morphological analyses of the boards. Melted sugars, which subsequently filled in the cell lumen void areas or acted as an adhesive fibre coating, were cited as a possible cause; this was further supported by the increase in lignin and cellulose content [8]. The results demonstrated that the addition of $20 \%$ glucose or $20 \%$ sucrose improved the MOR and IB of binderless boards made from oil palm trunks by $1.5-2$ times [8]. The maximum difference in hot water extractives content in this study was $4 \%$ and a strong positive correlation with MOR was observed, though the effect of hot water extractives was not isolated.

The results also showed a strong positive relationship between MOR and alcohol benzene extractives for $Q$. serrata samples (Fig. 4). Tannin, a substance classified as an alcohol benzene extractive (though at times also classified as a hot water extractive), is a key distinguishing feature between the chemical composition of $Q$. serrata and $Q$. acutissima. Tannin found in $Q$. serrata is predominantly comprised of hydrolyzable tannin, whereas $Q$. acutissima contains condensed tannin [21]. Hydrolyzable tannins are derivatives of gallic acid, which are esters linked to glucose. Incidentally, formic and acetic acid are released from lignocellulosic materials during the first stage of the hot press process [22]. Hydrolyzation of $Q$. serrata tannin during the hot press process may release glucose and enhance MOR through the abovementioned mechanisms $[8,10]$.

The effect of chemical components on IB was investigated (Fig. 5). IB showed a strong positive correlation with hot water extractives content $\left(R^{2}=0.7056, p=0.0364\right)$ and a moderate positive correlation with cellulose content $\left(R^{2}=0.5056, p=0.1136\right)$ for $Q$. acutissima samples. As mentioned previously, polymerization, melting and filling, thermal softening, and crosslinking are possible ways hot water extractives promotes internal bonding $[8,10]$. However, the results indicate that IB has a strong positive relationship with hot water extractives for $Q$. acutissima samples
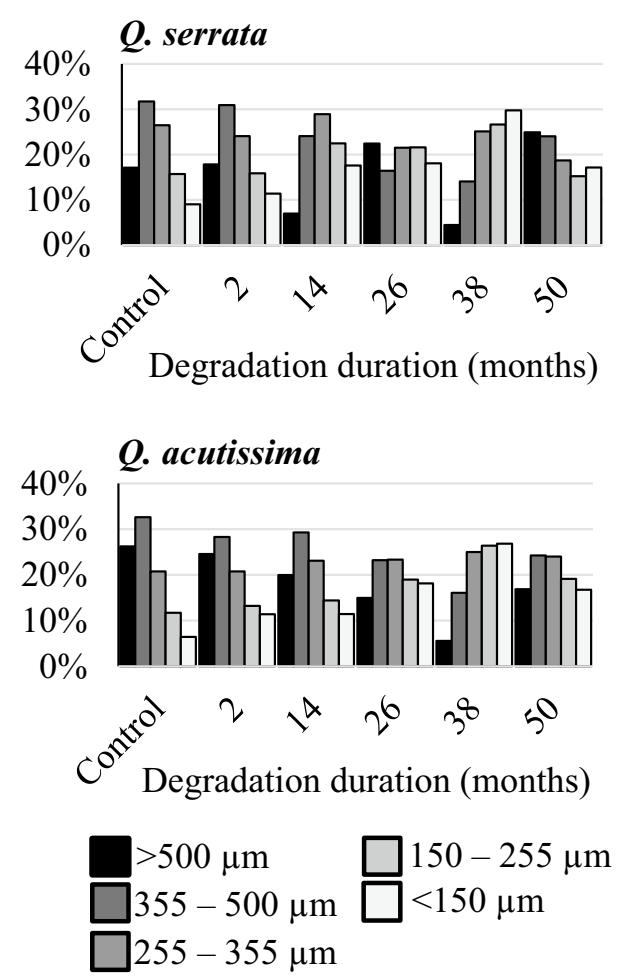

Fig. 6 Particle size distribution for $Q$. serrata and Q. acutissima WP 
only (Fig. 5). It can be observed from Fig. 3 that hot water extractives content of the two species begins to diverge from 14 months.

Shiitake fungi have been reported to degrade the cell walls of fibres and rays differently [23]. Fibre cells are degraded from the cell lumen out. Rays are degraded in a similar fashion initially, but the presence of an amorphous layer (defined by the author as a layer comprised of a protective layer and an isotropic layer that contains hemicellulose, pectic substances, cellulose microfibrils, and lignin) that follows a thin layer of inner cell wall prevents shiitake fungi from further degrading the cell wall from this direction [23]. Shiitake fungi then begins to degrade the cells from the middle lamella [23], a lignin-rich layer that binds the cells together. $Q$. acutissima has a higher percentage of ray cells, $19.7 \%$ compared to $9.7 \%$ for Quercus crispula, a species that is anatomically very similar to $Q$. serrata [24]. The differences in the hot water extractives and lignin content profiles exhibited in Fig. 3 may be due to the abovementioned differences in shiitake fungi behavior and anatomical features of the tree species: shiitake fungi are better able to degrade $Q$. serrata polysaccharides because of a lower proportion of ray cells, resulting in a higher concentration of hot water extractives content in the logs at an earlier stage; conversely, due to a higher proportion of ray cells, shiitake fungi are required to degrade the lignin-rich middle lamella in Q acutissima logs before it can access the polysaccharide-rich cell wall.

\section{Particle size distribution}

The particle size distribution of $Q$. serrata and $Q$. acutissima WP was investigated (Fig. 6). The results show that WP from logs degraded for longer durations had a higher proportion of $<250 \mu \mathrm{m}$ WP than the control and 2-month WP. The proportion of 355-500 $\mu \mathrm{m}$ WP showed the reverse trend; it was higher for the control and 2-month WP, but markedly lower
Fig. 7 Relationship between MOR of boards and the proportion of different sized particles of WP, on a species by species basis; a, b particles $>500 \mu \mathrm{m}$; c, d particles between 355 and $500 \mu \mathrm{m}$; e, f particles between 250 and $355 \mu \mathrm{m} ; \mathbf{g}, \mathbf{h}$ particles between 150 and $250 \mu \mathrm{m}$; and $\mathbf{i}$, j particles $<150 \mu \mathrm{m}$
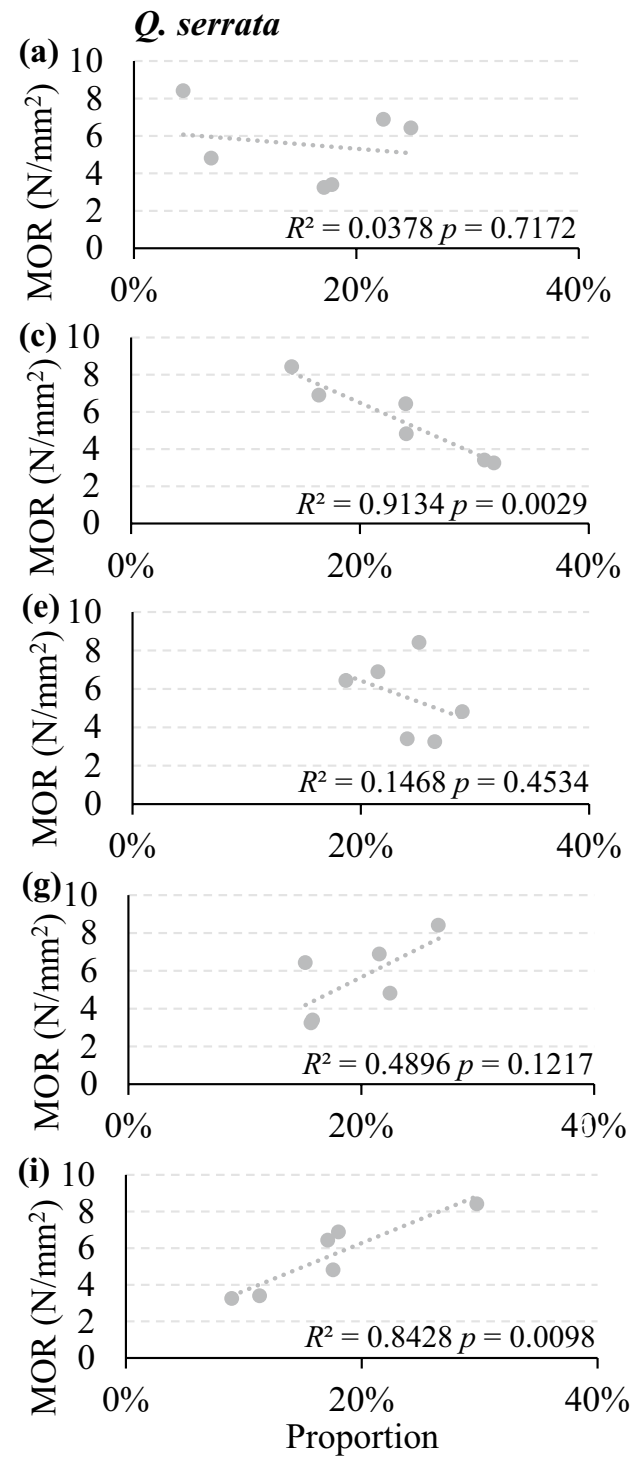

\section{Q. acutissima}
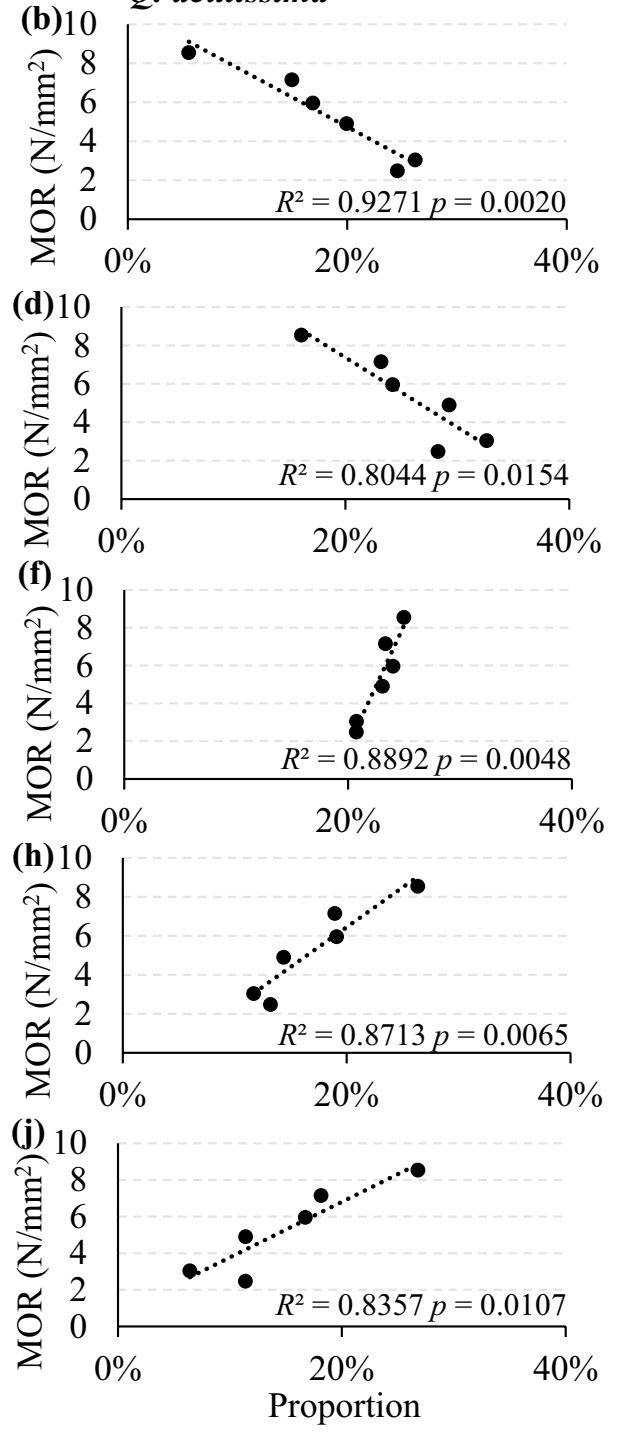
Fig. 8 Relationship between IB of boards and the proportion of different sized particles of WP, on a species by species basis; a, b particles $>500 \mu \mathrm{m}$; c, $\mathbf{d}$ particles between 355 and $500 \mu \mathrm{m} ; \mathbf{e}, \mathbf{f}$ particles between 250 and $355 \mu \mathrm{m} ; \mathbf{g}$, h particles between 150 and $250 \mu \mathrm{m}$; and $\mathbf{i}$, j particles $<150 \mu \mathrm{m}$
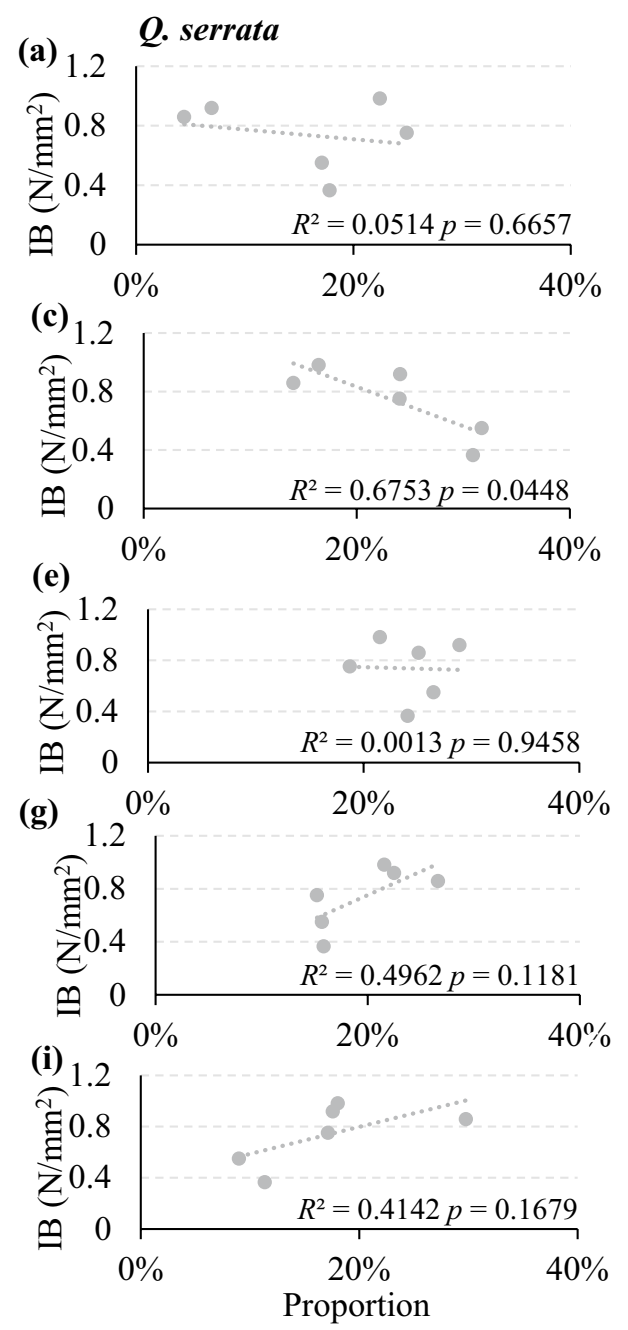
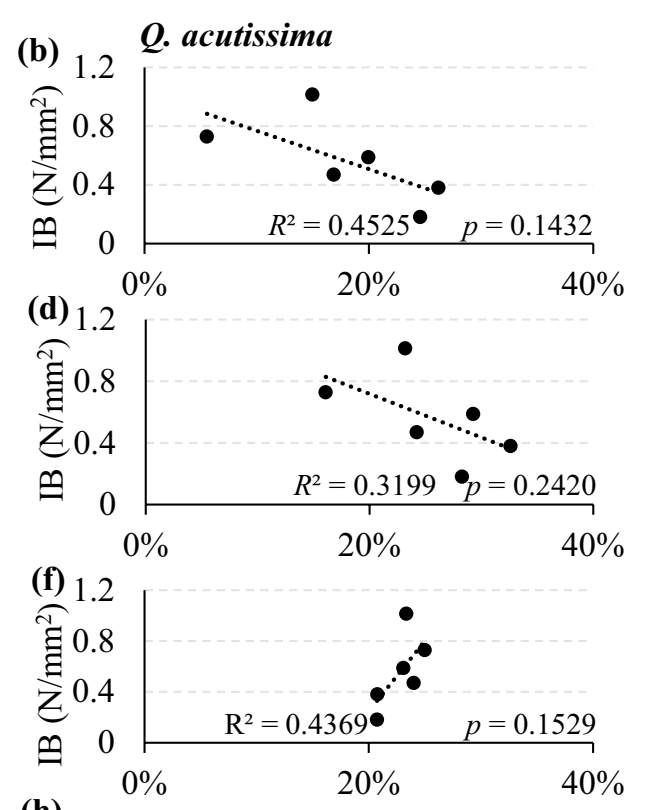
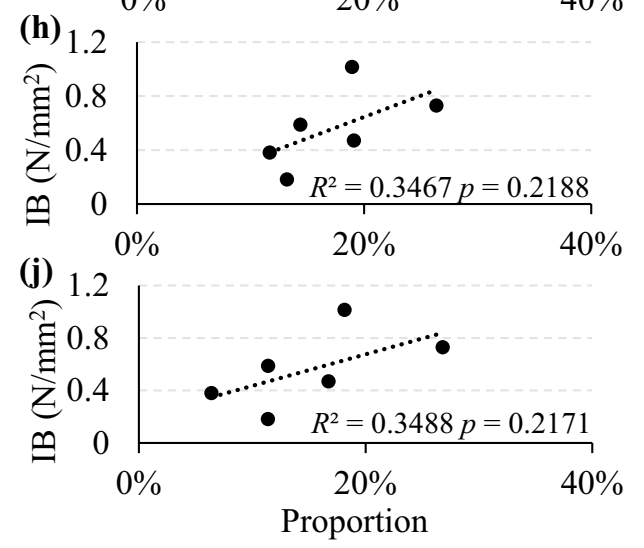

for WP from logs inoculated for longer durations. Shiitake fungi do not degrade all parts of a cell wall uniformly [23] and the voids created by the fungi become structural weaknesses of the cell that may potentially result in the collapse of cell walls during the milling process. Since the proportion of attacked cells increases with the degree of degradation, cells of logs that have a higher degree of degradation may have a higher tendency to collapse during the powderization process, thereby resulting in a larger proportion of small particles $(<250 \mu \mathrm{m})$ in the WP mixture.

The effect of particle size distribution on MOR was investigated (Fig. 7). The proportion of small particles $(<150 \mu \mathrm{m})$ had a very strong positive correlation with MOR for both species ( $Q$. serrata: $R^{2}=0.8428, p=0.0098 ; Q$. acutissima: $R^{2}=0.8357, p=0.0107$ ), whereas relatively large particles $(355-500 \mu \mathrm{m})$ had a very strong negative correlation with MOR (Q. serrata: $R^{2}=0.9134, p=0.0029 ; Q$. acutissima: $R^{2}=0.8044, p=0.0154$ ).

The effect of particle size distribution on IB was investigated (Fig. 8). Overall, the particle size distribution of
WP had a moderate effect on IB, with the proportion of 355-500 $\mu \mathrm{m} \mathrm{WP}$, in particular, having a strong negative correlation with IB for $Q$. serrata samples $\left(R^{2}\right.$ of 0.6753 and $p$ value of 0.0448).

The results of the particle size distribution analysis suggests that the physical characteristics of WP has a greater influence on MOR and IB than the chemical composition of the raw materials. A greater proportion of small particles may enhance particle packing [9] and decrease total surface void area [13], thereby enhancing stress transfer among the fibres and increasing MOR. Particle packing may also decrease the amount of voids in the matrix and increase the number of internal bonding sites, thereby improving IB [9].

The aim of the present study was to examine the effects of shiitake fungi degradation on the mechanical properties of binderless boards. Additional studies which isolate the influence of particle size distribution on board mechanical properties should be conducted by artificially changing the particle size distribution of undegraded Quercus spp. logs to similar ratios observed in the 26 or 38 -month samples of 
the present study. Further studies should elucidate the degree to which each chemical component and particle size class affects board mechanical properties.

\section{Conclusion}

Binderless boards made from $Q$. acutissima and $Q$. serrata $\log$ degraded by shiitake fungi for 26,38 , and 50 months during the mushroom cultivation process had higher MOR and IB values than the control. Binderless boards made from wood degraded for 26 (Q. acutissima: $1.01 \mathrm{~N} / \mathrm{mm}^{2}$ and $Q$. serrata: $0.98 \mathrm{~N} / \mathrm{mm}^{2}$ ) and 38 (Q. acutissima: $8.5 \mathrm{~N} / \mathrm{mm}^{2}$ and Q. serrata: $8.4 \mathrm{~N} / \mathrm{mm}^{2}$ ) months exhibited the strongest IB and MOR, respectively. Insights into possible factors driving the MOR and IB results were also gained.

MOR was influenced by a variety of factors, including degradation duration, hot water extractives content, lignin content, IB, and particle size distribution. In particular, there was a very strong positive and negative correlation between MOR and the proportion of small $(<250 \mu \mathrm{m})$ and large $(>500 \mu \mathrm{m}) \mathrm{WP}$, respectively. The greater number of contact points between fibres and a more efficient particle packing system are possible reasons smaller particles improve board bending strength.

Degradation duration and tree species had a statistically significant effect on IB. Hot water extractives content had a strong positive correlation with IB for $Q$. acutissima samples, but there was limited correlation between IB and the other chemical components and particle size distribution. A big IB difference between the control board and boards made from wood degraded for more than 2 months was observed.

Boards made from logs degraded for $\geq 26$ months exceeded the JIS Type 5 MOR and IB thresholds [17] of 5.0 and $0.2 \mathrm{~N} / \mathrm{mm}^{2}$, respectively.

Acknowledgements The authors express their deepest gratitude to Ms. Rie Yamashita (Industrial Research Institute of Shizuoka Prefecture) and Mr. Kiyoshi Shimura (MUSH-Shimura Farm) for their assistance in sourcing and collecting the raw materials. The authors also thank Dr. Kenji Aoki, Dr. Kei Maeda, and Mr. Akihiko Miyake for providing assistance with the mechanical tests.

\section{References}

1. Berglund L, Rowell RM (2005) Wood composites. In: Rowell RM (ed) Handbook of wood chemistry and wood composites. CRC Press LLC, Florida, pp 279-301

2. Kelly TJ, Smith DL, Satola J (1999) Emission rates of formaldehyde from materials and consumer products found in California homes. Environ Sci Technol 33:81-88

3. Okuda N, Sato M (2004) Manufacture and mechanical properties of binderless boards from kenaf core. J Wood Sci 50(1):53-61
4. Hashim R, Nadhari WNAW., Sulaiman O, Kawamura F, Hiziroglu S, Sato M, Sugimoto T, Seng TG, Tanaka R (2011) Characterization of raw materials and manufactured binderless particleboard from oil palm biomass. Mater Des 32(1):246-254

5. Saito Y, Ishii M, Sato M (2013) The suitable harvesting season and the part of moso bamboo (Phyllostachys pubescens) for producing binderless boards. Wood Sci Technol 47(5):1071-1081

6. Kurokochi Y, Sato M (2015) Properties of binderless board made from rice straw: the morphological effect of particles. Ind Crops Prod 69:55-59

7. Van Dam JE, Van den Oever MJ, Teunissen W, Keijsers ER, Peralta AG (2004) Process for production of high density/high performance binderless boards from whole coconut husk: Part 1: lignin as intrinsic thermosetting binder resin. Ind Crops Prod 19(3):207-216

8. Lamaming J, Sulaiman O, Sugimoto T, Hashim R, Said N, Sato M (2013) Influence of chemical components of oil palm on properties of binderless particleboard. BioResources 8(3):3358-3371

9. Marashdeh MW, Hashim R, Tajuddin AA, Bauk S, Sulaiman O (2011) Effect of particle size on the characterization of binderless particleboard made from Rhizophora spp. mangrove wood for use as phantom material. BioResources 6(4):4028-4044

10. Suzuki S, Shintani H, Park SY, Saito K, Laemsak N, Okuma M, Iiyama K (1998) Preparation of binderless boards from steam exploded pulps of oil palm (Elaeis guneensis) fronds and structural characteristics of lignin and wall polysaccharides in steam exploded pulps to be discussed for self-bindings. Holzforschung 52(4):417-426

11. Alvarez C, Rojano B, Almaza O, Rojas OJ, Gañán P (2011) Self-bonding boards from plantain fiber bundles after enzymatic treatment: adhesion improvement of lignocellulosic products by enzymatic pre-treatment. J Polym Environ 19(1):182-188

12. Leatham GF (1985) Extracellular enzymes produced by the cultivated mushroom Lentinus edodes during degradation of a lignocellulosic medium. Appl Environ Microbiol 50(4):859-867

13. Chiang TC, Hamdan S, Osman MSB (2015) The effect of weight fraction and size on the properties of sago particles urea formaldehyde particleboard. J Teknol 73(1):61-67

14. MAFF (2010-2015) Forestry products statistics. The statistical yearbook of the ministry of agriculture, Forestry and Fisheries Japan. http://www.maff.go.jp/j/tokei/kouhyou/ringyou_sansyutu/ index.html Accessed 27 Sept 2017; http://www.e-stat.go.jp/SG1/ estat/List.do?lid=000001172683 Accessed 27 Sept 2017

15. Kuroda K (2000) Kagaku (in Japanese). In: Japan Wood Society (ed) Mokushitsu Kagaku Jikken manual. Bunneido Shuppan, Tokyo, pp 92-97

16. Yoshihara K, Kobayashi T, Fujii T, Akamatsu I (1984) A novel modification of klason lignin quantitaitve method. TAPPI $\mathrm{J}$ 38(4):466-447

17. JIS A 5905 (2014) JIS standard specification for fiberboards. Japanese Standard Association, Tokyo

18. Rikuta N, Yonezawa Y, Tamio K (1968) Mokuzaikagaku volume I (in Japanese). Kyoritsu Shuppan, Tokyo, p 72

19. Lee JW, Koo BW, Choi JW, Choi DH, Choi IG (2008) Evaluation of waste mushroom logs as a potential biomass resource for the production of bioethanol. Bioresour Technol 99(8):2736-2741

20. Vane CH, Drage TC, Snape CE (2003) Biodegradation of oak (Quercus alba) wood during growth of the shiitake mushroom (Lentinula edodes): a molecular approach. J Agric Food Chem 51(4):947-956

21. Kishimoto J, Furukawa I, Sakuno T (1985) Comparison of konara (Quercus serrata) and kunugi (Quercus acutissima) bedlogs on the fruiting of shiitake mushroom (Lentinus edodes) (in Japanese). Koyoju Kenkyu 3:121-131 
22. Fahmy TY, Mobarak F (2013) Advanced binderless board-like green nanocomposites from undebarked cotton stalks and mechanism of self-bonding. Cellulose 20(3):1453-1457

23. Ohira I (1992) Mode of wood decomposition and fruiting body development of Lentinus edodes on Quercus serrata (in Japanese). Doctoral thesis, Tottori University, Japan
24. Fujiwara S, Sameshima K, Kuroda K, Takamura N (1991) Anatomy and properties of Japanese hardwoods volume I: variation of fiber dimensions and tissue proportions and their relation to basic density. IAWA J 12(4):419-424 